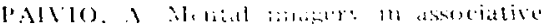
fearming ind memerve Psychological Revieti, $1969,76,2+1-2633$

PAIVIO, A. Imagery and perbal processes. New York: Holt, Rinehart and Winston. 1971

PAIVIO, A., \& BEGG, 1. Imagery and associative overlap in short-term memory. Research Bulletin No. 163, Department of Psychology, University of Western Ontario, 1970.

PAIVIO, $\wedge . . \&$ CSAPO, $K$. Concrete-image and verbal memory codes. Journal of Experimental Psychology, 1969, 80, 279-285.

PAIVIO, A., \& MADIGAN, S. Noun imagery and frequency in paired-associate and free recall learning. Canadian Journal of Psychology, 1970, 24, 353-361.

PAIVIO, A., \& O'NEILL, B. J. Visual recognition thresholds and dimensions of word meaning. Perception Psychophysics, 1970, 8, 273-275.

PAIVIO, A. YUILLE, J C.. \& MADIGAN, $S$. Concreteness, imagery, and meaningfulness values for 925 nouns. Journal of Experimental Psychology Monograph Supplement, 1968, 76(1. Pt. 2).

PETERSON, L. R., \& PETERSON, M. J. Short-term retention of individual verbal items. Journal of Experimental Psychology, 1959, 58, 193-198

SHEPARD, R. N. Recognition memory for words, sentences, and pictures. Journal of Verbal Learning \& Verbal Behavior $1967,6,156-163$.

UNDER WOOD, B. J., \& SCHULZ, R. W Meaningfulness and verbal learning. Chicago: Lippincott, 1960.

WICKENS, D. D., \& ENGLE, R. W. Imagery and abstractness in short-term memory. Journal of Experimental Psychology, $1970,84,268-272$

\title{
The effects of test events and spaced practice on free recall learning
}

\author{
ESTHER U. COKE
}

Bell Telephone Laboratories, Murray Hill, N.J. 07974

Two types of events, testing and a task unrelated to learning, were substituted for some practice trials during free recall learning. Three practice trials spaced by either of the substitute activities produced as much learning as seven massed practice trials. Statistically significant increases in recall over three criterion tests were not accompanied by increases in the stability of the recall sequence over successive criterion tests. The results of this experiment suggest that improvement in free recall performance due to repeated tests may be in part due to spaced practice.

Learning in an individual $S$ is frequently measured by test events interspersed throughout practice. This method of evaluating the learning process assumes that testing does not influence subsequent behavior. The results of a number of studies (Rothkopf \& Coke, 1963; Rothkopf, 1966; Lachman \& Laughery, 1968) indicate that this assumption is not always valid.

Tulving (1967) found that test trials could influence recall performance. He substituted two tests for two out of every three practice trials during free recall learning. This reduction in exposure to a word list did not affect the amount of material recalled. Tulving suggested that tests were as effective as practice because $\mathrm{S}$ was able to organize the material into larger memory units during a test.

The test trials in Tulving's experiment also interposed a time interval between successive practice trials. This spacing of practice might account for Tulving's results. The distribution of practice trials has been shown to affect the relationship between the number of exposures to material and its acquisition (Underwood, 1962; Rothkopf \& Coke, 1963).

In the present experiment, test trials or an activity of equal duration, but unrelated to learning, replaced some practice trials during free recall learning. According to Tulving's hypothesis about subjective organization, test trials may be as effective as practice trials in increasing recall. Further, if Tulving's characterization of the problem is correct, the substitution of an

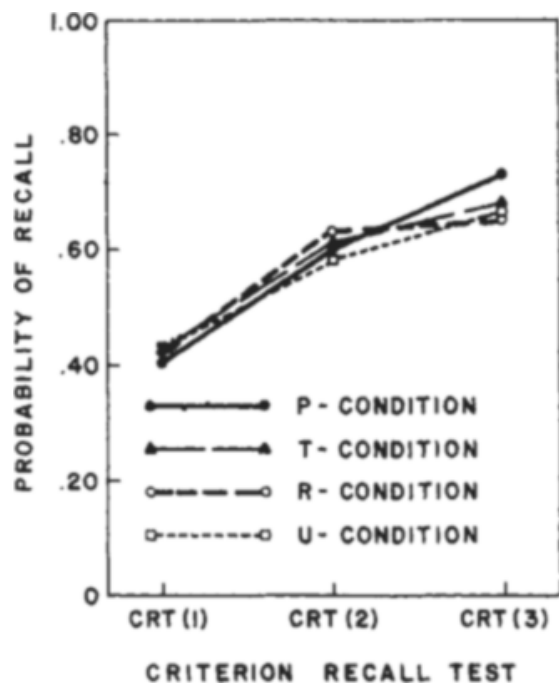

Fig. 1. The probability of recalling a word from the list as a function of the criterion recall test for each of the four experimental conditions. 
Table 1

The Sequence of Regular Practice Trials (RP), Criterion Recall Tests (CRT), and Interpolated Activities Making Up Each of the Four Experimental Conditions

\begin{tabular}{|c|c|c|c|c|c|c|c|c|}
\hline \multirow{2}{*}{$\begin{array}{l}\text { Condi- } \\
\text { tion }\end{array}$} & \multicolumn{8}{|c|}{ Sequence of Events } \\
\hline & 1 & 2 & $3^{*}$ & 4 & 5 & $6^{*}$ & 7 & 8 \\
\hline $\mathbf{P}$ & RP & CRT(1) & P Task & $\mathrm{RP}$ & CRT(2) & P Task & $\mathrm{RP}$ & CRT (3) \\
\hline $\mathrm{T}$ & $\mathbf{R P}$ & CRT(1) & T Task & $\mathrm{RP}$ & CRT(2) & T Task & RP & CRT(3) \\
\hline $\mathrm{R}$ & RP & CRT(1) & R Task & RP & CRT (2) & R Task & $\mathrm{RP}$ & CRT(3) \\
\hline $\mathrm{U}$ & RP & CRT(1) & U Task & RP & CRT (2) & U Task & RP & CRT (3) \\
\hline
\end{tabular}

* See the text for an explanation of the tasks in these phases.

unrelated activity for practice should alter the expected increase in recall as a function of trials, since subjective organization of the material would not be expected to develop during this activity.

\section{METHOD}

The $S$ saw 20 taxonomically unrelated one- and two-syllable English nouns. Words varied in frequency of usage from 9 to more than 100 per million and were approximately equally distributed over this range.

Experimental conditions differed from each other in the type of event interposed between a criterion recall test and the next regular practice trial, as shown in Table 1. During a regular practice trial (RP), each word was projected on a screen for $2 \mathrm{sec}$, with a 0.7 -sec interval between word presentations. Word order was varied at random from trial to trial, with $S$ instructed to learn the words in any order. Approximately $15 \mathrm{sec}$ after an $\mathrm{RP}$ trial, $\mathrm{S}$ was asked to recal! as many words as possible. The $S$ wrote each word on a separate card and turned it face down before the next response. This criterion recall test (CRT) was terminated after 60 sec. The activity interpolated between a CRT and the next RP trial took approximately $110 \mathrm{sec}$, including the time taken to instruct $S$.

The four experimental conditions were distinguished by the kind of activity interposed between CRT and the next RP, as follows. (1) The interpolated $P$ task of the $P$ condition consisted of two additional RP trials. (2) The T condition's interpolated T task was made up of two successive 40 -sec test trials with $\mathrm{S}$ instructed to recall as many words as possible on each test. (3) During the $R$ task of the

Table 2

Level of Subjective Organization Where SO(1) Was Based on CRT(1) and CRT(2) Performance, While SO(2) Was Based on CRT(2) and CRT(3) Performance

\begin{tabular}{ccc}
\hline Condition & SO(1) & SO(2) \\
\hline $\mathrm{P}$ & .00 & .04 \\
$\mathrm{~T}$ & .12 & .06 \\
$\mathrm{R}$ & .00 & .08 \\
$\mathrm{U}$ & .00 & .08 \\
\hline
\end{tabular}

$R$ condition, $S$ was asked to write down only those words that had not been recalled on the preceding CRT. ${ }^{1}$ (4) The U condition involved a $U$ task requiring $S$ to spend 80 sec canceling all zeros on a number of pages, each containing 600 randomly chosen numbers. The $S$ was instructed to work rapidly and accurately. Any $S$ who reported rehearsing the free-recall list during the $\mathrm{U}$ task was eliminated from the experiment.

Thirty-three Bell Telephone Laboratory clerks, ranging in age from 18 to 50 , participated in the experiment. One $\mathrm{S}$ was eliminated from the $U$ condition, leaving eight $\mathrm{Ss}$ in each experimental condition. RESULTS

The probabilities of recalling a word on the three CRT trials are shown in Fig. 1. An analysis of variance was performed after an arc-sin transformation of the data. The between-Ss treatment variable in this analysis was conditions $(P, T, R$, and $U$ conditions), and the within-Ss treatment variable was tests [CRT(1), CRT(2), and CRT(3)]. The analysis indicated that tests was a significant source of variance, $F(2,56)=55.99$, $p<.05$. Neither the effect of conditions nor the interaction between conditions and tests approached significance. Differences in recall on the three CRTs were evaluated over all Ss regardless of condition, using Duncan's multiple range test. All comparisons were significant $(\mathrm{p}<.05)$.

The subjective organization that developed during the experiment is shown in Table 2 and is expressed in terms of the index of organization (SO) suggested by Tulving (1962). This index measures the tendency of $\mathrm{S}$ to recall two words together in the same order on successive CRTs. SO(1) and $\mathrm{SO}(2)$ were based on recall protocols for CRT(1) and CRT(2) and for CRT(2) and CRT(3), respectively.

Table 2 indicates a slight increase in SO over the experimental session, but this change was not statistically significant (Wilcoxon matched-pairs signed-ranks test). As many Ss showed a decrease in SO as showed an increase, for all conditions. Although repeated testing ( $\mathrm{T}$ condition) seemed to produce sreater initial SO, a Kruskal-Wallis analysis of variance showed no significant difference between the four conditions on $\mathrm{SO}(1)$. DISCUSSION

The results of this experiment duplicated Tulving's (1967) finding that the replacement of some practice trials with test events did not affect recall performance. Three practice trials with tests interposed between them produced the same increase in recall as seven practice trials without the interpolated test activity.

This experiment also shows that the improvement in recall performance due to repeated testing observed by Tulving may be due in part to spaced practice. A task totally unrelated to the learning or testing procedures was used instead of test events to replace some practice trials. Performance of the unrelated task produced the same improvement in recall as repeated testing.

Tulving has argued that both practice and test events improve recall by increasing the size of memory units and that this increase can be measured as gains in subjective organization. No growth of subjective organization was observed in the present experiment, although there were significant increases in the number of words recalled. This may be accounted for in terms of the material used.

Despite this failure to find a growth in subjective organization, Tulving's results were replicated in the present study. Test events can influence the subsequent performance of Ss in a free recall learning situation. However, the present experiment suggests that at least part of the effect of testing on recall may be due to the spacing of practice trials by test events.

\section{REFERENCES}

LACHMAN, R. \& \& LAUGHERY, K. R. Is a test trial a training trial in free-recal learning? Journal of Experimental Psychology, 1968, 76, 40-50.

ROTHKOPF、E. Z. Learning from written instructional material: 1. An exploration of the control of behavior by test-like events. American Educational Research Journal, 1966, 3, 241-249.

ROTHKOPF. E. Z., \& COKE, E. U. Repetition interval and rehearsal method in learning equivalences from written sentences. Journal of Verbal Learning \& Verbal Behavior, 1963, 2, 406-416.

TULVING, E. Subjective organization in free recall of "unrelated" words Psychological Review, 1962, 67, 344-354. TULVING, E. The effects of presentation and recall of material in free-recall learning. Journal of Verbal Learning \& Verbal Behavior, 1967, 6, 175-184.

UNDERWOOD, B. J. Ten years of massed practice on distributed practice. Psychological Review, 1961, 68, 229-247. NOTE

1. The $R$ condition served as a control for the possibility that the motor activity of the $T$ condition's interpolated task might interfere with the development of subjective organization. 